\title{
PERANCANGAN SISTEM PEMETAAN BANTUAN SOSIAL BERBASIS WEB RESPONSIVE
}

\author{
Alif Catur Murti ${ }^{1}$, Agusta Praba Ristadi Pinem ${ }^{2}$ \\ ${ }^{1}$ Program Studi Teknik Informatika, Fakultas Teknik, Universitas Muria Kudus \\ ${ }^{2}$ Program Studi Sistem Informasi, Fakultas Teknologi Informasi dan Komunikasi, Universitas Semarang \\ Email: ${ }^{1}$ alif.catur@umk.ac.id, ${ }^{2}$ agusta.pinem@usm.ac.id
}

(Naskah masuk: 24 Juni 2020, diterima untuk diterbitkan: 29 Juni 2020)

\begin{abstract}
Abstrak
Pada masa pandemi Covid-19 yang memberi dampak di seluruh Dunia, tidak terkecuali di Indonesia. Setiap Negara memiliki kebijakan masing-masing unutuk menanganinya, mulai dari pemberlakuan Lockdown, Pembatasan Sosial Bersekala Besar (PSBB), sampai dengan New Normal. Semua kebijakan dilakukan untuk segera memutus rantai penyebaran Covid-19, karena semakin lama masyarakat dihadapkan dengan kondisi ekonomi yang melemah ketika pandemi ini tidak segara selesai. Upaya lain dari pemerintah adalah dengan memberikan bantuan sosial untuk masyarakat yang memiliki ekonomi lemah. Bantuan sosial tersebut diantaranya adalah Program Keluarga Harapan, Kartu Sembako, Kartu Prakerja, Pembebasan Tarif Listrik 450V, Bantuan Sosial Tunai, dan Bantuan Langsung Tunai. Kebijakan yang baik harus dikawal sehingga bantuan tersebut dapat tersalurkan sesuai sasaran. Aspek pemerataan bantuan juga menjadi penting sehingga tidak ada yang merasa dirugikan dari masyarakat yang membutuhkan. Berdasarkan kondisi tersebut perlu dirancang sebuah sistem pemetaan bantuan sosial yang transparan bisa diakses oleh siapa saja dengan model gadget apapun sehingga dapat membantu pemerintah ditingkat dinas dan desa untuk mengelola bantuan sosial secara efektif, efisien dan transparan dimata masyarakat.
\end{abstract}

Kata kunci: Sistem Pemetaan, WEB Responsive, Bantuan Sosial, Pandemi Covid-19

\section{DESIGNING OF RESPONSIVE WEB-BASED SOCIAL ASSISTANCE MAPPING SYSTEM}

\begin{abstract}
During the Covid-19 pandemic which had an impact all over the World, Including Indonesia. Each country has their respective policies to handle it, starting from the enactment of Lockdown, Large Scale Social Restrictions (PSBB), to the enforcement of New Normal. All policies were carried out to immediately break the chain of distribution of Covid-19, because the community was increasingly faced with a weak economic condition when the pandemic was not immediately finished. Another effort of the government is to provide social assistance to people who have a weak economy. The social assistance included the Keluarga Harapan Program, Food Packages, Pra-kerja Cards, Electricity Tariff Exemption, and Cash Social Assistance. A good policy must be guarded so that the assistance can be distributed according to the target. The aspect of equitable assistance is also important so that no one feels disadvantaged from the people in need. Based on these conditions a transparent social assistance mapping system needs to be designed that can be accessed by anyone with any gadget model so that it can help the government at the village and district level to manage social assistance effectively, efficiently and transparently in the eyes of the community.
\end{abstract}

Keywords: Mapping System, WEB Resopnsive Social Assistance, Pandemic Covid-19

\section{PENDAHULUAN}

Pada masa pandemi Covid-19 yang memberi dampak di seluruh Dunia, termasuk di Indonesia. Setiap Negara memiliki kebijakan masing-masing unutuk menanganinya, mulai dari pemberlakuan Lockdown, Pembatasan Sosial Bersekala Besar
(PSBB) , sampai dengan New Normal. Semua kebijakan dilakukan untuk segera memutus rantai penyebaran Covid-19, karena semakin lama masyarakat dihadapkan dengan kondisi ekonomi yang melemah ketika pandemi ini tidak segara selesai. 
Perlu adanya kesadaran dari masing-masing individu dan upaya dari semua lini. Upaya yang dapat dilakukan oleh masyarakat adalah dengan menjaga kebersihan diri, lingkungan serta mematuhi protocol kesehatan. Upaya lain dari pemerintah untuk membantu meringankan beban ekonomi masyarakat adalah dengan memberikan bantuan sosial. Sasaran akhir dari bantuan ini adalah masyarakat yang memiliki kondisi ekonomi lemah.

Bantuan sosial tersebut diantaranya adalah Program Keluarga Harapan, Kartu Sembako, Kartu Prakerja, Pembebasan Tarif Listrik 450V, Bantuan Sosial Tunai, dan Bantuan Langsung Tunai. Kebijakan yang baik harus dikawal sehingga bantuan tersebut dapat tersalurkan sesuai sasaran. Aspek pemerataan bantuan juga menjadi penting sehingga tidak ada yang merasa dirugikan dari masyarakat yang membutuhkan. Tuntutan masyarkat akan transparansi terkait penyaluran bantuan yang berasal dari pemerintah perlu direalisasikan. Berdasarkan kondisi tersebut perlu dirancang sebuah sistem pemetaan bantuan sosial yang transparan bisa diakses oleh siapa saja dengan model gadget apapun sehingga dapat membantu pemerintah ditingkat dinas dan desa untuk mengelola bantuan sosial secara efektif, efisien dan transparan dimata masyarakat.

\section{LANDASAN TEORI}

\subsection{Sistem}

Sistem adalah adalah bagian dari elemen-elemen yang berkumpul dan berinteraksi untuk menyelesaikan masalah untuk mencapai tujuan. Dimana dapat digambarkan sebagai data, program, maupun algoritma, Sistem dibangun untuk meunjukkan efektifitas dan efisien sebuah komponen yang saling terintegrasi (Jogiyanto, 2005), (Prahasta, 2005).

\subsection{Pemetaan}

Pemetaan adalah sebuah sistem yang didalamnya terdapat basis data dengan kemampuan khusus untuk merepresentasikan data secara spasial atau berupa koordinat geografis beserta sekumpulan operasi yang mengelola data tersebut. (Prahasta, 2005)

\subsection{Bantuan Sosial}

Bantuan Sosial adalah Bantuan Sosial adalah bantuan berupa uang, barang, atau jasa kepada seseorang, keluarga, kelompok atau masyarakat miskin, tidak mampu dan/atau rentan terhadap risiko sosial. (Peraturan Kemensos No 20, 2019),

\subsection{WEB Responsive}

WEB Responsive adalah kemampuan yang dimiliki oleh aplikasi khususnya yang berbasis WEB untuk bisa menyesuaikan tampilan terhadap resolusi layar dari berbagai macam gadget. Desain WEB yang responsive menjadi solusi dan sesuatu keharusan pada saat ini karena penggunaan berbagai macam gadget dengan resolusi yang berbeda-beda dan penggunaan internet yang sudah menjadi sebuah kebutuhan primer bagi masyarakat khususnya masyarakat Indonesia. (Syachbana dan Zulkarnain, 2014),(Virgunzena, dkk., 2014)

\section{TINJAUAN PUSTAKA}

Ada beberapa penelitian sebelumnya yang melandasi peulis untuk meneliti terkait dengan pemetaan bantuan sosial, penelitian tersebut diantaranya adalah penelitian yang dilakukan oleh Marlin Lasena dan Dedi Tambayong (2016) yang berjudul Sistem Informasi Geografis Bantuan Rumah Layak Huni Berbasis Web Pada Dinas Sosial Kabupaten Bolaang Mongondow Utara, membahas terkait efektifnya SIG yang digunakan untuk memperlihatkan informasi kepada masyarakat rumah mana saja yang berhak medapatkan bantuan dari pemerintah berupa Bantuan Rumah Layak Huni, sistem yang dibangun berbasis web dan bisa diakses diamana saja dan oleh siapa saja.

Mufidah (2011) melakukan penelitian terkait "Sistem Informasi Geografis (SIG) Pemetaan Lahan Pertanian Di Wilayah Mojokerto", pada penelitian ini menunjukkan bahawa sebuah sistem yang dibangun dan dikembangkan dengan informasi geografis / pemetaan mampu memaksimalkan penyempaian informasi. Sehingga pemetaan sebaran hasil produksi pertanian, struktur geologi, tingkat curah hujan dalam wilayah, dan tinggi rendahnya daerah diukur dari permukaan air laut dapat tersampaikan dengan baik ke masyarakat.

Sebuah sistem yang dibangun untuk memberikan kemudahan bagi pengguna akan lebih maksimal ketika informasi tersebut divisualisaikan dalam bentuk pemetaan, jika objek yang diteliti berhubungan dengan kondisi geografis.

\section{HASIL DAN PEMBAHASAN}

\subsection{Perancangan}

Perancangan yang dilakukan pada penelitian ini adalah menggunakan Unified Modeling Language (UML). Dimana untuk melihat apa saja yang bias dilakukan oleh pengguna/actor terlihat disini, pada gambar 1 . Meruapakan diagaram use case dari sistem pemetaan bantuan social.

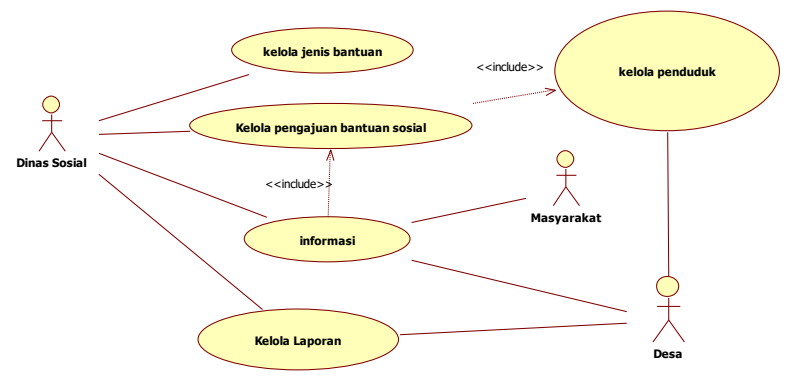

Gambar 1. Use Case Diagaram Sistem Pemetaan Bantuan Sosial Berbasis Web Responsive 
Dari gambar 1, dapat dideskripsikan sebagai berikut :

- Actor yang terlibat adalah Dinas Sosial, Desa dan Masyarakat.

- Masyarakat umum melihat informasi terkait dengan data penerima bantuan sosial sebagai bentuk transparansi.

- Desa bertugas mengelola data mulai dari data penduduk yang akan diajukan sebagai penerima bantuan beserta lokasi sesuai dengan lokasi geografis, informasi, dan laporan.

- Dinas Sosial bertugas mengelola dan melakukan proses persetujuan dan validasi penyaluran bantuan terhadap ajuan yang sudah dilakukan oleh desa.

Setelah use case terbentuk maka perlu adanya class diagaram untuk mengetahui class apa saja yang muncul untuk bisa dikembangkan kedalam perangkat lunak. Berikut ini adalah merupakan Class-class yang terbentuk:

\section{- Class Pengguna}

Class Pengguna yang terbentuk digunakan sebagai class yang menanmpung informasi terkait dengan pengguna sistem ini,gambar class Pengguna dapat dilihat pada gambar 2 .

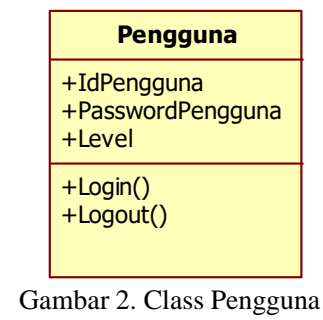

- Class Masyarakat Umum

Masyarakat umum memiliki operasi untuk melihat informasi penyaluran bansos. Gambar Class Umum dapat dilihat pada gambar 3 .

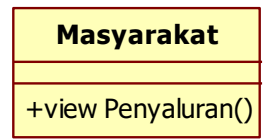

Gambar 3. Class Masyarakat

\section{- Class Desa}

Class Desa memiliki operasi untuk melakukan kelola data penduduk, dan data pengajuan penduduk untuk mendapatkan bantuan sosial. Class Desa dapat dilihat pada gambar 4.

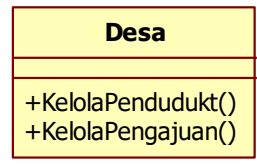

Gambar 4. Class Desa
- Class DinasSosial

Class DinasSosial memiliki beberapa oprerasi mulai dari kelola jenisbantuan, wilayah, pengguna, pengajuan, dan penyaluran. Gambar class DinasSosial dapat dilihat pada gambar 5.

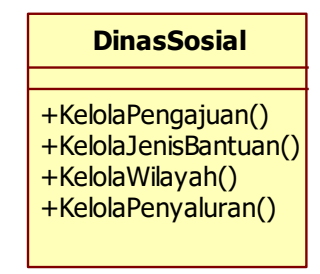

Gambar 5. Class DinasSosial

\section{- Class JenisBantuan}

Class JenisBantuan digunakan untuk menampung jenis bantuan sosial apa saja yang bisa diajukan oleh desa untuk penduduknya, jenis bantuan ini menyesuaikan sesuai kebijakan dari pemerintah. Class JenisBantuan dapat dilihar pada gambar 6.

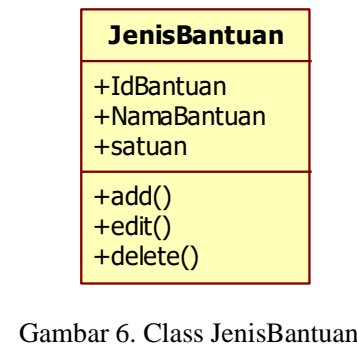

\section{- Class Wilayah}

Class Wilayah digunakan untuk menampung data wilayah yang tercover oleh DinasSosial. Gambar 7 adalah gambar class Wlayah.

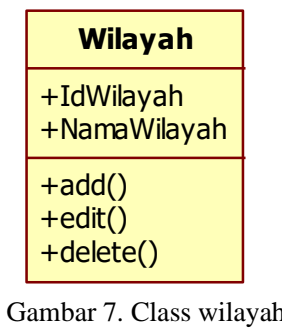

- Class Penduduk

Class Penduduk digunakan untuk menampung data dari penduduk yang ada diwilayah desa tertentu. Pada gambar 8 menunjukkan class wilayah. 


\begin{tabular}{|l|}
\hline \multicolumn{1}{|c|}{ Penduduk } \\
\hline +NIK \\
+KK \\
+ nama \\
+alamat \\
+ rt \\
+ rw \\
\hline +add() \\
+edit() \\
+dekete() \\
\hline
\end{tabular}

Gambar 8. Class Penduduk

\section{- Class Pengajuan}

Class pegajuan ini digunakan untuk mengajukan penduduk yang berhak mendapatkan bantuan, tetapi keputusan penerimaan dan jumlah realisasi tergantung dari dinas sosial. Dengan adanya pengajuan ini terlihat histori penduduk tersebut sudah pernah diajukan bantuan atau belum. Class pengajuan dapat dilihat pada gambar 9 .

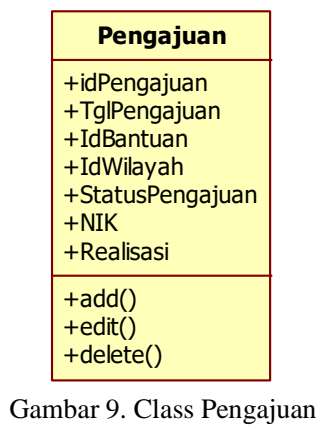

\section{- Class Penyaluran}

Class penyaluran digunakan untuk menampung hasil validasi penyaluran ke penduduk yang telah dajukan. Class Penyauran bantuan dapat dilihat pada gambar 10 .

\begin{tabular}{|l|}
\hline \multicolumn{1}{|c|}{ Penyaluran } \\
\hline +IdPenyaluran \\
+TgIPenyaluran \\
+IdPengajuan \\
+PengajuanGeom \\
+JmIRealisasi \\
+satuan \\
+IdPengguna \\
\hline
\end{tabular}

Gambar 10. Class Penyaluran

Dari beberapa class yang terbentuk dapat dilihar Class Diagram Sistem Pemetaan Bantuan Sosial pada gambar 11.

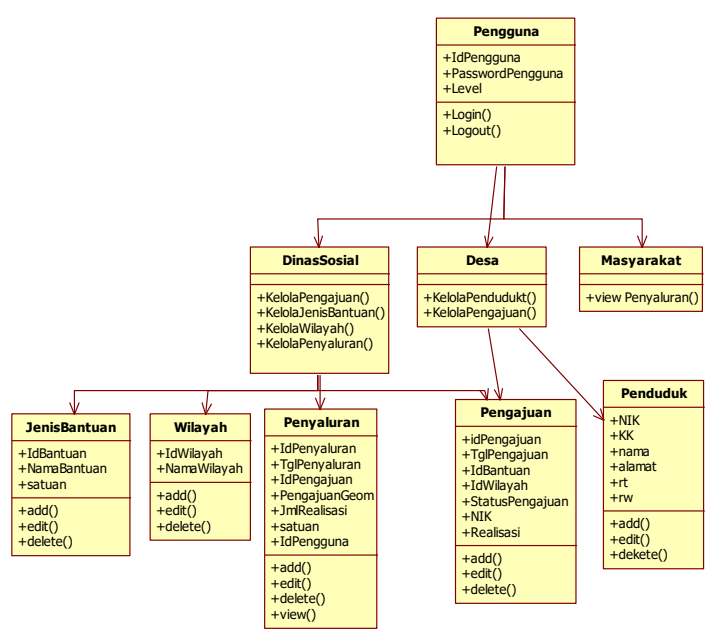

Gambar 11. Class Diagram Sistem Pemetaan Bantuan Sosial Berbasis WEB Responsive

\subsection{Implementasi}

Pada tahap implementasi kita dapat melihat kesesuaian anatara perancangan dengan hasil dari yang dibuat.

Halaman Login ini akan berada pada awal sebelum pengguna masuk kedalam sistem, manajemen pengguna dilakukan oleh Dinsos dan unuk masyarakat umum tinggal masuk dengan klik langsung pada tombol Masuk sebagai masyarakat. Gambar 12 merupakan halaman Login.

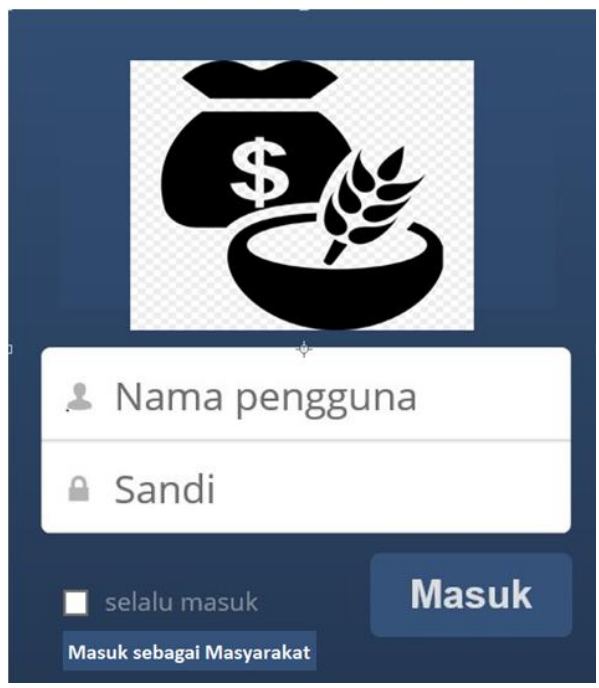

Gambar 12. Gambar Login

Dalam melakukan pengajuan baru dilakukan pada halaman pengajuan bantuan, seperti yang terlihat pada gambar 13. Pengajuan dilakukan oleh pengguna dengan level desa. Pada halaman ini juga bisa terlihat histori pengajuan yang sudah dilakukan oleh desa dan penduduk yang diajukan. 


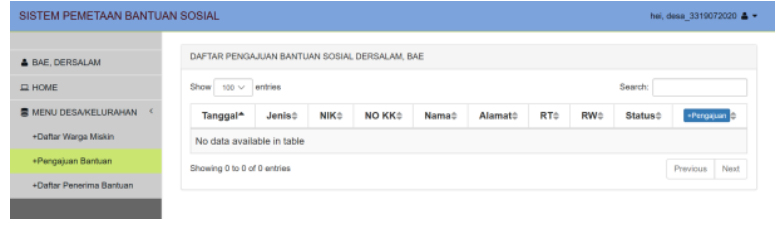

Gambar 13. Halaman pengajuan bantuan

Setelah melakukan klik pada tambah pengajuan maka pengguna desa akan dibawa ke halaman input pengajuan bantuan, sesuai dengan data penduduk yang ada di wilayah desa tersebut. Gambar 14 adalah merupakan halaman input pengajuan. Pada saat input data pengajuan bantuan untuk penduduk desa juga menentukan lokasi rumah dari penduduk yang mengajukan bantuan.

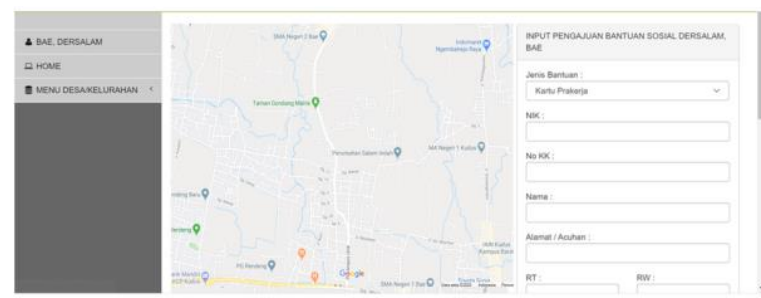

Gambar 14. Halaman input pengajuan bantuan

Pada halaman Jenis bantuan yang dilihat pada gambar 15, digunakan untuk menambahkan jenis bantuan yang berikan oleh pemerintah seperti bantuan Program Keluarga Harapan, Kartu Sembako, Kartu Prakerja, Pembebasan Tarif Listrik 450V, Bantuan Sosial Tunai, dan Bantuan Langsung Tunai.

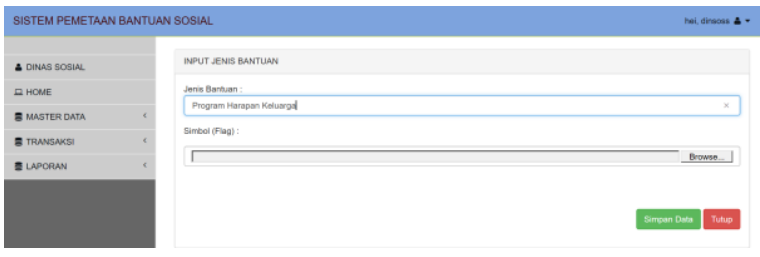

Gambar 15. Halaman input jenis bantuan

\subsection{Analisa WEB Responsive}

Memang menjadi suatu keharusan pada saat ini untuk mengembangkan web dengan menerapkan web responsive, karena menjadi sebuah solusi dari munculnya berbagai macam gadget dan model alat komunikasi. Sistem ini diuji dengan membandingkan tampilan melalui PC/Laptop, IPAD, dan Smart phone Android yang memiliki resolusi layar yang berbeda. Hasil tampilan aplikasi dapat dilihat pada gambar 16.
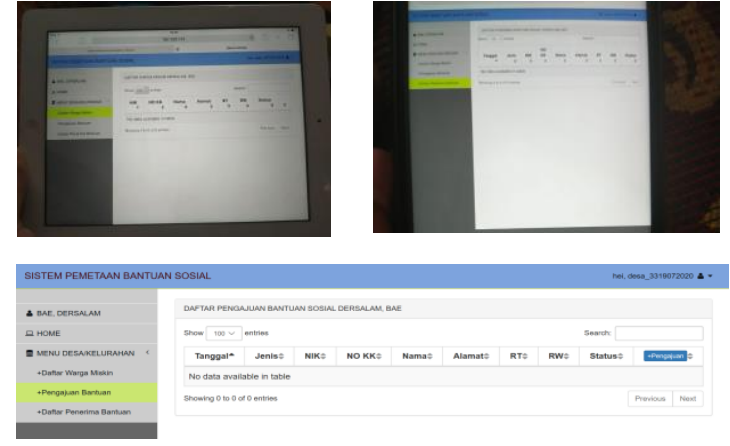

Gambar 16. Perbandingan tampilan dibeberapa gadget

Dari hasil perbandingan tersebut dapat dikatakan bahwa sistem pemetaan bantuan sosial berbasis web responsive dapat dijalankan di gadget yang berbeda-beda tanpa mengurangi penyampaian informasi.

\section{KESIMPULAN}

Melihat hasil dari pembahasan dan analisa dari perancangan yang sudah dibuat maka dapat disimpulkan bahawa :

1. Dengan memanfaatkan sistem pemetaan bantuan sosial, Penyaluran bantuan dapat bersifat transparan, merata dan dapat tersalurakan kepada yang berhak, terlebih lagi kondisi ekonomi yang menurun seperti sekarang ini akibat pandemi covid-19.

2. Data yang tersimpan dalam histori meminimalisir adanya dana bantuan sosial ganda yang diterima oleh penduduk.

3. Pengembangan sistem berbasis WEB Responsive memberikan solusi dengan munculnya berbagai macam gadget sekarang ini.

\section{DAFTAR PUSTAKA}

Jogiyanto, 2005, Analisis dan Disain Sistem Informasi, Andi Offset, Yogyakarta.

Lasena, M., \& Tambayong, D., 2016, Sistem Informasi Geografis Bantuan Rumah Layak Huni Berbasis Web Pada Dinas Sosial Kabupaten Bolaang Mongondow Utara, Teknosains, Vol 10 No 1, 89-103

Prahasta, Eddy., 2006, Sistem Informasi Geografis: Tutorial Arcview, Informatika,

Peraturan Kementrian Sosial nomor 20 tahun 2019 tentang Penyaluran Bantuan Pangan Nontunai. Jakarta: Kementerian Sosial Negara Republik Indonesia.

Retno, Mufidah., 2011, Sistem Informasi Geografis (SIG) Pemetaan Lahan Pertanian Di Wilayah Mojokerto, Fakultas Teknik, PENS

Syachbana dan Zulkarnain A., Perancangan Website Menggunakan Responsive Web Design, Jurnal SIGMATA, Vol. 2, No. 1, 22-27 
54 Indonesian Journal of Technology, Informatics and Science (IJTIS), Vol. 1, No. 2, Juni 2020, hlm. 49-54

Virgunzena, B, A., Sudiarta, P, K., Suyadnya, I, M, A., 2014, Rancang Bangun Aplikasi Pemetaan Coverage Area Berbasis Web Responsive Sebagai Alat Simulasi Perencanaan Pembangunan Tower Telekomunikasi, Teknologi Elektro, Vol 13 No 2, 48-54 